\title{
Influence of magnesium sulphate infusion before total thyroidectomy on transient hypocalcemia - a randomised study
}

\author{
Nikola Besic, Spela Zagar, Gasper Pilko, Barbara Peric, Marko Hocevar \\ Department of Surgical Oncology, Institute of Oncology, Ljubljana, Slovenia
}

\begin{abstract}
Background. Transient hypocalcemia is the most common complication after thyroidectomy. Normomagnesemia is needed for normal secretion of PTH and end-organ responsiveness. Our aim was to determine the influence of infusion of magnesium sulphate before thyroidectomy on the incidence of laboratory and clinical transient hypocalcemia.

Methods. In our prospective study, 48 patients (5 men, 43 women; age 22-73 years, median 45 years), who underwent total or near-total thyroidectomy, were randomised preoperatively. Half of them received intravenously $4 \mathrm{ml}$ of $1 \mathrm{M}$ magnesium sulphate at the beginning of the surgical procedure, the other half were the control group. Serum concentrations of calcium, ionised calcium, magnesium, phosphate, albumin and PTH were measured prior to surgery and on the first day after surgery.

Results. Laboratory postoperative hypocalcemia was present in $27 \%$ of patients and $23 \%$ of patients had clinical signs and/or symptoms of postoperative hypocalcemia. The concentration of total calcium $(p=0.024)$ and of albumin ( $p=0.01$ ) was lower in the group that received magnesium sulphate.

Conclusions. The patients who received infusion of magnesium sulphate before total thyroidectomy had lower concentration of total serum calcium and albumin in comparison to the control group. There was no statistical difference in the incidence of clinical transient hypocalcemia.
\end{abstract}

Key words: magnesium sulphate; transient hypocalcemia; randomised study; total thyroidectomy

This paper is a part of the Research studies No. J30570 supported by the Ministry of Education, Science and Sport of Slovenia.

Received 26 August 2008 Accepted 5 September 2008

Correspondence to: Assist. Prof. Nikola Besic, MD, $\mathrm{PhD}$, Department of Surgical Oncology, Institute of Oncology, Zaloska 2, SI-1000 Ljubljana. Phone: +386 15879953 ; Fax: +386 15879400 ; E-mail: nbesic@ onko-i.si

\section{Introduction}

Transient hypocalcemia is the most common complication after total thyroidectomy (TT) and usually fades away in a few days. ${ }^{1}$ The incidence of transient hypocalcemia after total thyroidectomy is $6.2-68 \% .^{2,3}$ Transient hypocalcemia may be very unpleasant to the patient. It may entail a few 
Table 1. Characteristics of 48 patients

\begin{tabular}{|c|c|c|}
\hline Factor & Subgroup & $\begin{array}{l}\text { Number of } \\
\text { patients (\%) }\end{array}$ \\
\hline \multirow{2}{*}{ Gender } & Male & $5 \quad(10)$ \\
\hline & Female & $43(90)$ \\
\hline \multirow{2}{*}{ Aplication of magnesium sulfate } & Yes & $24 \quad(50)$ \\
\hline & No & $24(50)$ \\
\hline \multirow{2}{*}{ Ca lower $(<2.1 \mathrm{mmol} / \mathrm{L})$ postoperatively } & Yes & $13(27)$ \\
\hline & No & $35(73)$ \\
\hline \multirow{2}{*}{$\begin{array}{l}\text { Ionised Ca lower }(<1.12 \mathrm{mmol} / \mathrm{L}) \\
\text { postoperatively }\end{array}$} & Yes & $23(52)$ \\
\hline & No & $21(48)$ \\
\hline \multirow{2}{*}{$\begin{array}{l}\text { Mg lower }(<0.7 \mathrm{mmol} / \mathrm{L}) \\
\text { Postoperatively }\end{array}$} & Yes & $3 \quad(6)$ \\
\hline & No & $45(94)$ \\
\hline \multirow{2}{*}{ PTH lower (<12 ng/L) postoperatively } & Yes & $6 \quad(13)$ \\
\hline & No & $40(78)$ \\
\hline \multirow{2}{*}{ Albumin lower $(<34 \mathrm{~g} / \mathrm{L})$ postoperatively } & Yes & $4 \quad(9)$ \\
\hline & No & $40(91)$ \\
\hline \multirow{2}{*}{ Paresthesia postoperatively } & Yes & $9 \quad(19)$ \\
\hline & No & $39(81)$ \\
\hline \multirow{2}{*}{ Muscular spasms postoperatively } & Yes & $2 \quad(4)$ \\
\hline & No & $46(96)$ \\
\hline \multirow{2}{*}{ Chvostek's sign postoperatively } & Yes & $7 \quad(15)$ \\
\hline & No & $41 \quad(85)$ \\
\hline \multirow{2}{*}{ Symptoms/signs of postoperative hypocalcemia } & Yes & $11(23)$ \\
\hline & No & $37(77)$ \\
\hline \multirow{2}{*}{ Therapy of postoperative hypocalcemia } & Yes & $15(31)$ \\
\hline & No & $33(69)$ \\
\hline \multirow{2}{*}{ Histologicaly parathyroid tissue in bioptic sample } & Yes & $5 \quad(10)$ \\
\hline & No & $43(90)$ \\
\hline \multirow{2}{*}{ Permanent hypocalcemia } & Yes & $(0)$ \\
\hline & No & $100(0)$ \\
\hline
\end{tabular}

more laboratory tests and sometimes longer hospitalisation, thus increasing treatment costs.

Many authors tried to find out how to prevent postoperative hypocalcemia. To our knowledge only three prospective randomised studies were done. ${ }^{4-6}$ Bellantone et al. ${ }^{5}$ and Tartaglia et al. ${ }^{6}$ treated their patients with oral calcium salts and calcitriol. Uruno et al. proved that prophylactic infusion of diluted calcium after total thyroidectomy can effectively inhibit the development of symptomatic hypocalcemia. ${ }^{4}$ But it should be noted that intravenous application of calcium may cause thrombophlebitis or even skin necrosis. On the other hand, magnesium is known to have an impact on the calcium homeostasis in the serum, ${ }^{7}$ whereas parenetral application of magnesium sulphate is safe and without 
side effects. ${ }^{8}$ The aim of our study was to verify whether intravenous application of 4 $\mathrm{ml}$ of $1 \mathrm{M}$ magnesium sulphate before thyroidectomy reduces the occurrence of laboratory and clinically transient postoperative hypocalcemia.

\section{Patients and methods}

Only the patients who gave their informed consent were included in our study. The study was approved by the Protocol Review Board and Committee for Medical Ethics at the Institute of Oncology Ljubljana and by the Medical Ethics Committee of the Republic of Slovenia (Ref. No. 29/02/05) and was performed in accordance with the medical ethics standards laid down in Declaration of Helsinki of 1975, as revised in 1983.

In our prospective study, 48 adult patients ( 5 men, 43 women; age range 22-73 years, median 45 years) who underwent total or near-total thyroidectomy were preoperatively randomised into two groups. Half of the patients received intravenously $4 \mathrm{ml}$ of $1 \mathrm{M}$ magnesium sulphate after induction of anaesthesia and immediately after skin incision (before thyroid part of surgical procedure); the other half of the patients were in the control group. Total or near-total thyroidectomies were performed from May 2005 to June 2006 at the Institute of Oncology Ljubljana, by two surgeons, both experienced in thyroid surgery. The patients with lymph node dissection of the central neck compartment, hyperthyroidism, hypercalcemia or renal insufficiency were not included in the study. None of our patients was preoperatively treated with antireabsorbtive drugs, diuretics, antiepileptics or with supplementation of calcium, vitamin D or magnesium.

Total or near-total thyroidectomy was performed because of benign goiter and follicular neoplasm in 14 and 34 patients, respectively. Among patients wilth follicular neoplasm, a definitive histology showed follicular variant of papillary carcinoma, follicular carcinoma and follicular adenoma in 19, 4 and 11 patients, respectively.

Serum concentrations of calcium, ionised calcium, magnesium, phosphate, albumin and PTH were measured prior to surgery and on the first day after surgery. When hypocalcemia was detected postoperatively, the serum concentration of calcium, magnesium, phosphate, albumin and PTH was measured till the normalisation of laboratory results (daily during the first week after the operation and once in the second week).

In order to detect a statistical difference between the groups and $10 \%$ change in serum calcium concentration (i.e. $0.2 \mathrm{mmol} /$ L) with our sample size (i.e. 24 patients in each group), the power calculation for our trial showed that it was $90 \%$.

\section{Laboratory hypocalcemia}

Hypocalcemia was defined as transient if: (1) serum calcium concentration dropped to the value lower than $2.1 \mathrm{mmol} / \mathrm{L}$ and (2) hypocalcemia faded away in six months. A cut-point concentration value of low serum ionized calcium was $1.12 \mathrm{mmol} / \mathrm{L}$, and of low PTH, it was $12 \mathrm{ng} / \mathrm{L}$.

If hypocalcemia is present after 6 months, it is permanent. Permanent hypocalcemia was present if vitamin D supplementation was still required six months after thyroidectomy.

\section{Clinical hypocalcemia}

The presence of the symptoms and/or signs of transient hypocalcemia was followed by the two surgeons and their team and registered into a special questionnaire. In the first four days after the operation 
Table 2. Comparison of preoperative and postoperative laboratory values in the group of patients having received the magnesium sulphate infusion (Group 1) and the other that had not (Group 2)

\begin{tabular}{|c|c|c|c|c|c|}
\hline Factor & Group & $\begin{array}{c}\text { Preoperative median } \\
\text { value }\end{array}$ & P-value & $\begin{array}{c}\text { Postoperative median } \\
\text { value }\end{array}$ & P-value \\
\hline \multirow{2}{*}{$\begin{array}{l}\text { Calcium } \\
(\mathrm{mmol} / \mathrm{L})\end{array}$} & 1 & 2.40 & \multirow{2}{*}{0.316} & 2.11 & \multirow{2}{*}{0.024} \\
\hline & 2 & 2.42 & & 2.20 & \\
\hline \multirow{2}{*}{$\begin{array}{l}\text { Ionised calcium } \\
(\mathrm{mmol} / \mathrm{L})\end{array}$} & 1 & 1.22 & \multirow{2}{*}{0.437} & 1.10 & \multirow{2}{*}{0.235} \\
\hline & 2 & 1.23 & & 1.13 & \\
\hline \multirow{2}{*}{$\begin{array}{l}\text { Magnesium } \\
(\mathrm{mmol} / \mathrm{L})\end{array}$} & 1 & 0.87 & \multirow{2}{*}{0.636} & 0.82 & \multirow{2}{*}{0.670} \\
\hline & 2 & 0.88 & & 0.81 & \\
\hline \multirow{2}{*}{$\begin{array}{l}\text { Phosphate } \\
(\mathrm{mmol} / \mathrm{L})\end{array}$} & 1 & 1.10 & \multirow{2}{*}{0.103} & 1.36 & \multirow{2}{*}{0.288} \\
\hline & 2 & 1.17 & & 1.29 & \\
\hline \multirow{2}{*}{$\begin{array}{l}\text { Albumin } \\
(\mathrm{g} / \mathrm{L})\end{array}$} & 1 & 43.9 & \multirow{2}{*}{0.144} & 37.3 & \multirow{2}{*}{0.010} \\
\hline & 2 & 45.1 & & 40.4 & \\
\hline \multirow{2}{*}{$\begin{array}{l}\text { PTH } \\
(\mathrm{ng} / \mathrm{L})\end{array}$} & 1 & 14.4 & \multirow{2}{*}{0.619} & 27.6 & \multirow{2}{*}{0.331} \\
\hline & 2 & 17.5 & & 32.3 & \\
\hline
\end{tabular}

the following symptoms and/or signs of transient hypocalcemia were registered: paresthesias, spasm, carpopedal spasm, and Chvostek's sign. Chvostek's sign was regarded as positive when a facial muscle spasm was induced by the percussion of the facial nerve. Clinical transient hypocalcemia was defined as the occurrence of any of its symptoms (limb or perioral parasthesia, cramps) and/or signs (carpopedal spasm, Chvostek's sign) that developed after thyroidectomy and faded away in six months.

The data about patients' age and gender, pathological diagnosis, presence of parathyroid tissue in bioptic specimen, laboratory results, presence of clinical signs and symptoms of hypocalcemia, duration of hospitalisation and therapy of hypocalcemia were collected. Hospitalisation was defined as the time interval from surgery to the day of release from the hospital. Any therapy (i.v. or oral administration of calcitriol, calcium salts or magnesium salts) applied postoperatively was specified as postoperative treatment of hypocalcemia.

\section{Statistical analysis}

The patients were divided into two groups: the first one that received an intraoperative infusion of magnesium sulphate and the other that did not. We compared the preoperative and postoperative data of the first group to those of the other one. Analysis of variance was used for the evaluation of the effect of magnesium sulphate infusion on the continuous laboratory variables (calcium, magnesium, phosphate, albumins and PTH), whereas the effect of magnesium sulphate infusion on nonparametric variables (clinical hypocalcemia) was analysed by Fischer's exact test. The analysis of variance was also used for the comparison of duration of hospitalisations of both groups, while Fisher's exact test was used for the comparison of the rate of patients in both groups requiring postoperative treatment of hypocalcemia. Statistical analysis was made by the computer program SPSS for Windows, version 13.0 (SPSS Inc., 2004). 


\section{Results}

Characteristics of the patients are presented in Table 1. Before thyroidectomy, the concentration of calcium, ionised calcium, magnesium, phosphate, albumin and PTH of the first group did not significantly differ from those of the second group (Table 2). The first day after the operation (Table 2), serum calcium concentration was lower in the group having received the magnesium sulphate infusion in comparison to the control group $(\mathrm{p}=0.024)$. Postoperative serum albumin concentration was lower in the group having received the magnesium sulphate infusion in comparison to the control group $(\mathrm{p}=0.01)$.

The comparison of the occurrence of symptoms and/or signs of postoperative hypocalcemia did not show any statistically significant difference between the patients who received the magnesium sulphate infusion and those who did not (Table 3).

The duration of hospitalisation of the group that received magnesium sulphate did not significantly differ from that of the control group $(p=0.370)$. The proportion of patients who were treated for hypocalcemia was not significantly different in the patients who received magnesium sulphate in comparison to the control group $(\mathrm{p}$ $=0.755$ ).

Pathological examination confirmed the presence of parathyroid gland tissue in the bioptic material of five patients, while in the bioptic material of the remaining 43 patients, no parathyroid tissue was detected. The concentrations of calcium $(p=0.013)$, ionised calcium $(p=0.06)$, and PTH ( $\mathrm{p}=0.007)$, measured postoperatively, were lower in the group of patients with histologically confirmed presence of parathyroid tissue, whereas the phosphate concentration in this group of patients was higher than in other patients.

\section{Discussion}

Pathophysiological mechanism of postoperative hypocalcemia after total thyroidectomy has not been fully explained; but, it has been agreed that it is definitely multifactorial. Potential mechanisms causing transient hypocalcemia after total thyroidectomy are: transient perioperative hemodilution, ${ }^{9,10}$ increased calcitonin release, ${ }^{11,12}$ abnormal functioning of the parathyroid glands due to edematous gland or transient insufficiency in blood supply, ${ }^{13}$ and impairment or unintentional excision of the parathyroid gland. ${ }^{9,14,15}$ Some parathyroid glands may be anatomically intact; however, their function may nevertheless be physiologically impaired because of parathyroid arteria occlusion or edematous gland. ${ }^{16,17}$ Intraoperative change of the colour of parathyroid is believed to be an indicator of insufficient blood supply; however, Ander et al. proved that the disorders in the microcirculation of parathyroid glands are not related to their macroscopic appearance. ${ }^{18}$ We claim that, in our case, the experience of the surgeon could not significantly affect the outcome of surgery because both surgeons applied similar surgical procedures and were also equally skilled. The incidence of an incidentally detected parathyroid tissue in histologic material $(10.5 \%)$ is comparable to that in other similar studies, yet still at lower level of the incidence range reported in the literature (9-15\%). ${ }^{19-21}$

The incidence of transient hypocalcemia after thyroidectomy reported in the literature differs from study to study ${ }^{14,22-26}$ due to the differences in the reference calcium values of laboratory test, definitions of laboratory transient hypocalcemia and clinical transient hypocalcemia. In our study, the rate of the patients with laboratory transient hypocalcemia (27\%) and those with clinically transient hypocalcemia (23\%) was in the interval of $6.2-68 \%$, which was simi- 
Table 3. Comparison of symptomps and/or signs of hypocalcemia in the group of patients having received the magnesium sulphate infusion (Group 1) and the other that had not (Group 2)

\begin{tabular}{lccc}
\hline $\begin{array}{l}\text { Symptom / sign of } \\
\text { hypocalcemia }\end{array}$ & Group & $\begin{array}{c}\text { Patients with } \\
\text { Symptom/sign }\end{array}$ & $\begin{array}{c}\text { P-value } \\
\text { (fisher's exact test) }\end{array}$ \\
\hline Paresthesia & 1 & 6 & 0.46 \\
\hline Muscular spasms & 2 & 3 & 1.000 \\
\hline \multirow{2}{*}{ Chvostek's sign } & 1 & 1 & 1.000 \\
\hline \multirow{2}{*}{ Any symptom or sign } & 2 & 4 & \multirow{2}{*}{1.000} \\
\hline
\end{tabular}

lar to that reported in the literature. . $2,3,14,22-26^{2}$ In the study by Wilson et al., in which the definitions of laboratory and clinical hypocalcemia are similar to the definitions in our study, $68 \%$ of patients were diagnosed with laboratory transient hypocalcemia and 36\% of patients had symptoms of hypocalcemia. ${ }^{3}$ They defined hypomagnesemia as serum concentration of magnesium lower than 0.7 $\mathrm{mmol} / \mathrm{L}$ and the same definition was used in our study. They reported that the incidence of postoperative hypomagnesemia was considerably higher $(72 \%)$ than that in our patients who did not receive infusion of magnesium sulphate (2/24 patients, i.e $8 \%$ ). It is established that hypomagnesemia may well contribute to postoperative tetany after total thyroidectomy, especially with concomitant hypocalcemia. ${ }^{3}$ Possibly, the cause of hipomagnesemia in the study by Wilson et al. ${ }^{3}$ is the volume of fluids that were given. The volume of fluids correlated with hypomagnesemia ( $\mathrm{p}=0.027)$. Namely, the patients with severe hypomagnesemia were given on average of 4.93 liters during the 24-hour perioperative period, compared to 4.69 liters in mild hypomagnesemia and 3.64 liters in normomagnesemia patients. ${ }^{3}$ Our patients during the 24-hour perioperative period were given only 1.5 to 2.5 liters of fluids. There was no statistical difference of the given volume of fluids in the group of our patients who received intraoperative infusion of magnesium sulphate in comparison to the control group.

The results of our study demonstrate that intraoperative infusion of magnesium sulphate does not reduce the incidence of laboratory hypocalcemia. On the contrary, the first day after operation, the total serum concentration of calcium was statistically significantly lower $(p=0.032)$ in the group of patients who received intraoperative infusion of magnesium sulphate in comparison to the control group. A possible mechanism which could be the reason of the decreased total serum calcium concentration is the drop of PTH serum concentration caused by the infusion of magnesium sulphate. This assumption was supported by the study in which magnesium was infused to healthy subjects; ${ }^{27}$ the PTH serum concentration dropped significantly in five minutes after the infusion. ${ }^{27}$ But, the two groups of patients in our study do not differ significantly between each other either in the PTH serum concentration or in ionised calcium concentration the first day after the operation; therefore, the above mechanism does not provide a satisfactory explanation of the drop of calcium concentration in the group of patients who received magnesium sulphate infusion. 
Another mechanism which could be the cause of the decreased total serum calcium concentration is the drop of albumin concentration. The total serum calcium concentration depends, in fact, on the albumin concentration. One gram of albumins binds approximately $0.7 \mathrm{mg}$ of calcium. Falk et al. observed that a significant drop of albumin concentration occured the first and the second day after thyroidectomy. ${ }^{28}$ They assumed that the decreased concentration of the albumin induced by non-specific release of antidiuretic hormone (ADH) and hemodilution. ${ }^{28}$ This might have been the most probable mechanism that decreased the total calcium concentration in our patients who were treated with magnesium sulphate infusion. Significantly lower total serum calcium concentration $(p=0.024)$ and lower serum albumin concentration $(p$ $=0.01$ ) was observed in the group of patients with application of magnesion sulphate in comparison to the control group. The mechanism of a more intense drop of albumin as a consequence of magnesium sulphate application has so far not been clarified and needs further investigation. ${ }^{29,30}$

In terms of the incidence of postoperative clinical simptoms and/or signs of hypocalcemia, no statistically significant difference was observed between the two groups of patients. This was predictable from the laboratory test results. In the group treated with magnesium sulphate infusion, a statistically significantly lower total calcium concentration was observed in comparison to the control group, whereas the concentration of ionised calcium as well as PTH was not significantly different. As ionised calcium is a more reliable indicator of laboratory and clinical hypocalcemia than the total calcium concentration, ${ }^{28}$ it is understandable that the proportion of the patients with clinical hypocalcemia was the same in both groups of patients. Furthermore, it is also logical that there were no statistically significant differences between the two groups in the rate of the patients who were treated for hypocalcemia. In addition, there were no statistically significant differences between the two groups in the duration of hospitalisation.

\section{Conclusions}

The patients who are treated with intraoperative magnesium sulphate infusion have statistically significantly lower total calcium and albumine concentration than the patients in the control group. The two groups of patients does not differ significantly in the incidence of the transient clinical hypocalcemia, the duration of hospitalisation or the rate of patients who were treated for hypocalcemia.

\section{References}

1. Rosato L, Avenia N, Bernante P, De Palma M, Gulino G, Nasi PG, et al. Complications of thyroid surgery: analysis of a multicentric study on 14,934 patients operated on in Italy over 5 years. World J Surg 2004; 28: 271-6.

2. Bhattacharyya N, Fried MP. Assessment of the morbidity and complications of total thyroidectomy. Arch Otolaryngol Head Neck Surg 2002; 128: 389-92.

3. Wilson RB, Erskine C, Crowe PJ. Hypomagnesemia and hypocalcemia after thyroidectomy: prospective study. World J Surg 2000; 24: 722-6.

4. Uruno T, Miyauchi A, Shimizu K, Tomoda C, Takamura Y, Ito Y, et al. A prophylactic infusion of calcium solution reduces the risk of symptomatic hypocalcemia in patients after total thyroidectomy. World J Surg 2006; 30: 304-8.

5. Bellantone R, Lombardi C, Raffaelli M, Boscherini $\mathrm{M}$, Alesina PF, De Crea $C$, et al. Is routine supplementation therapy (calcium and vitamin D) useful after total thyroidectomy? Surgery 2002; 132: 110912. 
6. Tartaglia F, Giuliani A, Sgueglia M, Biancari F, Juvonen T, Campana FP. Randomized study on oral administration of calcitriol to prevent symptomatic hypocalcemia after total thyroidectomy. Am J Surg 2005; 190: 424-9.

7. Levine BS, Coburn JW. Magnesium, the mimic/ antagonist to calcium. $N$ Engl J Med 1984; 310: 1253-5.

8. Hamill-Ruth RJ, McGory R. Magnesium repletion and its effect on potassium homeostasis in critically ill adults: results of a double-blind, randomized, controlled trial. Crit Care Med 1996; 24: 38-45.

9. Sturniolo G, Lo Schiavio MG, Tonante A, D'Alia C, Bonanno L. Hypocalcemia and hypoparathyroidism after total thyroidectomy: a clinical biological study and surgical considerations. Int J Surg Investig 2000; 2: 99-105.

10. Demeester-Mirkine N, Hooghe L, Van Geertruyden J, De Maertelaer V. Hypocalcemia after thyroidectomy. Arch Surg 1992; 127: 854-8.

11. Watson CG, Steed DL, Robinson AG, Deftos LJ. The role of calcitonin and parathyroid hormone in the pathogenesis of post-thyroidectomy hypocalcemia. Metabolism 1981; 30: 588-9.

12. Rasmusson B, Borgeskov S, Holm-Hansen B. Changes in serum calcitonin in patients undergoing thyroid surgery. Acta Chir Scand 1980; 146: 15-7.

13. Warren FM, Andersen PE, Wax MK, Cohen JI. Perioperative parathyroid hormone levels in thyroid surgery: preliminary report. Laryngoscope 2004; 114: 689-93.

14. Pattou F, Combemale F, Fabre S, Carnaille B, Decoulx M, Wemeau JL, et al. Hypocalcemia following thyroid surgery: incidence and prediction of outcome. World J Surg 1998; 22: 718-24.

15. Davis RH, Fourman P, Smith JW. Prevalence of parathyroid insufficiency after thyroidectomy. Lancet 1963; 2: 121-4.

16. Palazzo FF, Sywak MS, Sidhu SB, Barraclough BH, Delbridge LW. Parathyroid autotransplantation during total thyroidectomy--does the number of glands transplanted affect outcome? World J Surg 2005; 29: 629-31.

17. Delbridge L. Parathyroid autotransplantation: an essential technique for safe thyroid surgery. ANZ J Surg 2002; 72: 852-3.

18. Ander S, Johansson K, Smeds S. In situ preservation of the parathyroid glands during operations on the Thyroid. Eur J Surg 1997; 163: 33-7.
19. Lee NJ, Blakey JD, Bhuta S, Calcaterra TC. Unintentional parathyroidectomy during thyroidectomy. Laryngoscope 1999; 109: 1238-40.

20. Sasson AR, Pingpank JF Jr, Wetherington RW, Hanlon AL, Ridge JA. Incidental parathyroidectomy during thyroid surgery does not cause transient symptomatic hypocalcemia. Arch Otolaryngol Head Neck Surg 2001; 127: 304-8.

21. Lin DT, Patel SG, Shaha AR, Singh B, Shah JP. Incidence of inadvertent parathyroid removal during thyroidectomy. Laryngoscope 2002; 112: 608-11.

22. Lo CY, Lam KY. Postoperative hypocalcemia in patients who did or did not undergo parathyroid autotransplantation during thyroidectomy: a comparative study. Surgery 1998; 124: 1081-6.

23. Lam A, Kerr PD. Parathyroid hormone: an early predictor of postthyroidectomy hypocalcemia. Laryngoscope 2003; 113: 2196-200.

24. Higgins KM, Mandell D, Govindaraj S, Genden EM, Mechanick JI, Bergman DA, et al. The role of intraoperative rapid parathyroid hormone monitoring for predicting thyroidectomy-related hypocalcemia. Arch Otolaryngol Head Neck Surg 2004; 130: 63-7.

25. Scurry WC Jr, Beus KS, Hollenbeak CS, Stack BC Jr. Perioperative parathyroid hormone assay for diagnosis and management of postthyroidectomy hypocalcemia. Laryngoscope 2005; 115: 1362-6.

26. Payne RJ, Hier MP, Tamilia M, Mac Namara E, Young J, Black MJ. Same-day discharge after total thyroidectomy: the value of 6-hour serum parathyroid hormone and calcium levels. Head Neck 2005; 27: $1-7$.

27. Fatemi S, Ryzen E, Flores J, Endres DB, Rude RK. Effect of experimental human magnesium depletion on parathyroid hormone secretion and 1,25dihydroxyvitamin D metabolism. J Clin Endocrinol Metab 1991; 73: 1067-72.

28. Falk SA, Birken EA, Baran DT. Temporary postthyroidectomy hypocalcemia. Arch Otolaryngol Head Neck Surg 1988; 114: 168-74.

29. The Magpie Trial: a randomised trial comparing magnesium sulphate with placebo for pre-eclampsia. Outcome for women at 2 years. Bjog 2007; 114: 300-9.

30. Duley L. Evidence and practice: the magnesium sulphate story. Best Pract Res Clin Obstet Gynaecol 2005; 19: 57-74. 